JURNAL ILMIAH MUQODDIMAH:

Jurnal IImu Sosial, Politik Dan Humaniora

\title{
PERBEDAAN KUALITAS LAYANAN PENDIDIKAN DI SMA NEGERI 16 PALEMBANG DAN SMA YPI TUNAS BANGSA PALEMBANG
}

\author{
Rizki Aulia ${ }^{1)}$, Abdullah Idi $^{2)}$, Yoyok Hendarso ${ }^{3)}$ \\ Fakultas IImu Sosial IImu Politik Universitas Sriwijaya \\ rizkiiaulia37@gmail.com ${ }^{1}$ \\ abdullahidi@unsri.ac.id ${ }^{2}$ \\ yoyokhendarso@unsri.ac.id ${ }^{3}$
}

\begin{abstract}
Abstrak
Indonesia berusaha agar pendidikan nasional di Indonesia lebih baik, sehingga Sisdiknas dituangkan dalam UU No. 20 tahun 2003, yang memiliki visi misi menjadi lebih maju dan lebih berkembang, akan tetapi nyatanya kualitas pendidikan di Indonesia masih memiliki berbagai kendala. Data World Education Ranking yang diterbitkan Organization for Economic Cooperation and Develomnet (OECD). Permasalahan dalam penelitian ini adalah: 1) Bagaimana kualitas layanan pendidikan pada siswa SMA Negeri 16 Palembang dan YPI Tunas Bangsa Palembang? 2) Apakah ada perbedaan kualitas layanan pendidikan untuk siswa di SMA Negeri 16 Palembang dan YPI Tunas Bangsa Palembang? Tujuan dari penelitian ini adalah untuk mengetahui: 1) kualitas layanan pendidikan di SMA Negeri 16 Palembang dan SMA YPI Tunas Bangsa Palembang; 2) perbedaan kualitas layanan pendidikan untuk siswa di SMA Negeri 16 Palembang dan YPI Tunas Bangsa Palembang. Desain ini menggunakan penelitian komparatif yaitu penelitian yang membandingkan, atau dalam bentuk hubungan sebab akibat antara dua atau lebih variabel. Populasi penelitian adalah semua siswa SMA Negeri 16 Palembang dan YPI Tunas Bangsa Palembang, sedangkan teknik pengambilan sampel menggunakan rumus Slovin dengan total 336 orang. Teknik pengumpulan data menggunakan kuesioner, sedangkan teknik analisis data menggunakan uji $t$ dengan bantuan program SPSS for windows. Berdasarkan hasil penelitian kualitas layanan pendidikan untuk siswa di SMA Negeri 16 Palembang termasuk dalam kategori baik, sedangkan kualitas layanan pendidikan.
\end{abstract}

Kata Kunci: Kualitas, Layanan, Pendidikan

\begin{abstract}
Indonesia is trying to make national education in Indonesia better, so the National Education System is outlined in Law no. 20 of 2003, which has a vision and mission to be more advanced and more developed, but in fact the quality of education in Indonesia still has various obstacles. World Education Ranking data published by the Organization for Economic Cooperation and Development (OECD). The problems in this study are: 1) How is the quality of education services in high school students 16 Palembang and YPI Tunas Bangsa Palembang? 2) Is there a difference in the quality of educational services for students in SMA Negeri 16 Palembang and YPI Tunas Bangsa Palembang? The purpose of this study was to determine: 1) the quality of educational services in SMA Negeri 16 Palembang and SMA YPI Tunas Bangsa Palembang; 2) the difference in the quality of educational services for students at SMA Negeri 16 Palembang and YPI Tunas Bangsa Palembang. This design uses comparative research that is research that compares, or in the form of a causal relationship between two or more variables. The study population was all students of SMA Negeri 16 Palembang and YPI Tunas Bangsa Palembang, while the sampling technique used the Slovin formula with a total of 336 people. Data collection techniques using questionnaires, while data analysis techniques using $t$ test with the help of SPSS for windows program. Based on the results of research the quality of education services for students in SMA Negeri 16 Palembang is included in the good category, while the quality of education services.
\end{abstract}

Keywords: Quality, Service, Education 


\section{PENDAHULUAN}

Indonesia sebagai salah satu negara yang sedang berkembang baik dari bidang ekonomi, sosial, politik dan budaya maupun dibidang pendidikan pada saat masih berusaha agar pendidikan menjadi lebih baik. Dalam hal lain, Indonesia juga berusaha berpedoman pada Sisdiknas dengan harapan dapat menjadikan bangsa Indonesia menjadi lebih maju dan lebih berkembang. Visi dan misi Sisdiknas tersedia dalam UU No. 20 tahun 2003 yaitu terwujudnya sistem pendidikan sebagai pranata sosial yang kuat dan berwibawa untuk memberdayakan semua warga Negara Indonesia berkembang menjadi manusia yang berkualitas sehingga mampu dan proaktif menjawab tantangan zaman yang selalu berubah." Misinya adalah "Mengupayakan perluasan dan pemerataan kesempatan mempero-leh pendidikan yang bermutu bagi seluruh rakyat (UU RI SISDKNAS: 41).

Nyatanya kualitas pendidikan di Indonesia masih memiliki berbagai kendala. Data World Education Ranking yang diterbitkan Organization for Economic Cooperation and Develomnet (OECD) seperti yang dilansir The Guardian tahun 2016, disebutkan bahwa Indonesia menempati peringkat ke-57 dari total 65 negara di dunia, sedangkan untuk minat baca, menurut Most Litered Nation in the Worlddalam CCS Universitytahun 2016, peringkat kualitas di negara Indonesia berada pada nomor ke-60 dari 61 negara. Selanjutnya, Baswedan dalam Widodo (2015) menyatakan bahwa status pendidikan di Indonesia berada dalam yang kurang baik.

Beberapa hal yang menunjukkan kondisi di atas antara lain: (1) Indonesia memiliki pelayanan pendidikan yang rendah, (2) kualitas pendidikan di Indonesia juga rendahnya, (3) rendahnya kemampuan dan keterampilan peserta didik di Indonesia. Kenyataan ini menunjukkan bahwa hingga saat ini pendidikan di Indonesia banyak mengalami permasalahan dan juga rintangan.Kondisi ini tentu akan berpengaruh secara langsung terhadap kelulusan yang dihasilkan. Dengan mutu pendidikan yang rendah tentu kualitas lulusan yang dihasilkan juga akan rendah.
Departemen Pendidikan Nasional telah menyelenggarakan perbaikanperbaikan peningkatan mutu pendidikan pada berbagai jenis jenjang. Namun, fakta di lapangan belum menunjukkan hasil yang memuaskan. Keberhasilan tersebut tentu melibatkan banyak faktor sehingga diperlukan perubahan dan harus diperbaharui. Faktor tersebut seperti guru, penggunaan media atau alat pembelajaran, penggunaan metode, strategi pembelajaran, ataupun model pembelajaran, maupun aspek lingkungan. Unsur-unsur tersebut saling berkaitan dan sling mendukung sehingga terciptanya pendidikan yang lebih baik. Namun, berbagai kendala dihadapi untuk tujuan proses pendidikan adalah rendahnya hasil belajar peserta didik. Hal ini tentu menjadi perhatian guru maupun pendidik agar dapat meningkatkan hasil belajar peserta didik dari setiap jenjang yang paling dasar sampai ke jenjang berikutnya yang lebih tinggi.

Di Indonesia terdapat berbagai jenis sekolah yang berdasarkan penyelenggaraannya dibagi menjadi sekolah negeri dan sekolah swasta. Sekolah yang diselenggarakan oleh pemerintah disebut dengan sekolah negeri, sedangkan sekolah swasta diterapkanyayasan. Dilihat dari cara pengelolaannya, susunan organisasi dan wewenang sekolah negeri ditetapkan oleh Menteri Pendidikan dan menjadi tanggung jawab pemerintah, sedangkan susunan organisasi dan wewenang sekolah swasta ditetapkan dan menjadi tanggung jawab badan penyelenggaranya atau yayasan. Dengan adanya perbedaan jenis sekolah tersebut, maka terdapat pula perbedaan karakter antara sekolah negeri dan sekolah swasta, dimana perbedaan-perbedaan ini dapat mempengaruhi perkembangan psikososial peserta didik pada setiap jenis sekolah.

Keadaan sekolah swasta yang dikelola oleh yayasan menyebabkan biaya operasional dibebankan kepada peserta didik, sehingga biaya pendidikan di sekolah swasta menjadi lebih mahal dari biaya pendidikan di sekolah negeri yang ditanggung oleh pemerintah. Oleh sebab itu, biasanya jumlah peserta didik di sekolah swasta relatif lebih kecil dibandingkan 
dengan jumlah peserta didik di sekolah negeri. Dari sisi ini, dapat dilihat bahwa peserta didik yang bersekolah di sekolah swasta memiliki lingkungan pergaulan yang cenderung homogen, karena peserta didik dan siswi yang bersekolah di sekolah swasta memiliki teman bergaul yang berasal dari latar belakang ekonomi yang kurang lebih sama. Hal ini berbeda dengan di sekolah negeri yang biaya pendidikannya lebih murah, dimana peserta didik dan siswinya memiliki teman dari latar belakang ekonomi yang beragam. Karena perbedaan lingkungan pergaulan ini, murid sekolah swasta memiliki komunitas yang lebih dekat satu sama lain, dimana tingkat dukungan sosial dan kontrol sosial di sekolah swasta akan menjadi lebih tinggi dari sekolah negeri (Watt, 2003 dalam Bachrie, 2009).

Perbedaan kualitas pendidikan di SMA Negeri 16 Palembang dan SMA YPI Tunas Bangsa belum diketahui secara pasti. Berdasarkan Rekap Hasil Ujian Nasional Kementrian Pendidikan dan Kebudayaan tahun 2017, peringkat pertama pada Program Studi IPA ditempati oleh SMA swasta yaitu SMA Ignatius Global School dengan rata-rata 85,17 , sedangkan peringkat kedua ditempati oleh SMA negeri yaitu SMA Sumatera Selatan dengan ratarata 76,78 . Peringkat ketiga juga ditempati oleh SMA Swasta, sedangkan peringkat keempat ditempati oleh SMA Negeri. Pada Program Studi IPS, peringkat pertama dan kedua ditempati oleh SMA Negeri yaitu SMA Sumatera Selatan dan SMAN 17 Palembang, sedangkan pada peringkat ketiga dan keempat ditempati oleh SMA swasta yaitu SMA Harapan dan SMA Kusuma Bangsa.

Selain itu, menurut Mendikbud (2016), penilaian kualitas pendidikan harus menyeluruh. Penilaian atau evaluasi terhadap mutu pendidikan tidak hanya berfokus pada peserta didik, guru, kepala sekolah, serta orang tua secara terpisah. Keempat elemen tersebut harus menjadi satu kesatuan ekosistem dalam penyelenggaraan pendidikan peserta didik.

Selanjutnya, aspek kualitas yang juga harus dipenuhi oleh sekolah adalah kualitas layanan. Wyckof dalam Lovelock (2010:75) menyatakan bahwa kualitas layanan sebagai tingkat kesempurnaan yang diharapkan dan pengendalian atas kesempurnaan tersebut untuk memenuhi keinginan konsumen, sedangkan menurut Parasuraman dan Berry (1988) kualitas layanan merupakan perbandingan antara layanan yang dirasakan (persepsi) konsumen dengan kualitas layanan yang diharapkan konsumen. Jika kualitas layanan yang dirasakan sama atau melebihi kualitas layanan yang diharapkan, maka layanan dikatakan berkualitas dan memuaskan. Lovelock (2010:91) juga menyatakan bahwa dasar bagi loyalitas sejati terletak pada kepuasan pelanggan, di mana kualitas layanan menjadi input utamanya. Pelanggan yang sangat puas atau bahkan yang menyenangi layanan cenderung menjadi pendukung loyal perusahaan. Wijaya (2011:1) juga menjelaskan bahwa kualitas dan layanan memiliki kedudukan yang sangat penting di semua aktivitas atau kegiatan. Dalam bidang pendidikan dan bidang industri, unsur tersebut menjadi berfungsi karena memiliki perbedaan yang paling efektif. Organisasi pendidikan juga banyak menerapakan bermacam strategi untuk meningkatkan hasil yang maksimal, salah satunya melalui strategi kualitas. Salah satunya adalah sekolah yang merupakan lembaga formal dan menyiapkan serta menyediakan pelayanan jasa dalam bidang pendidikan juga menerapkan strategi tersebut dapat meningkatkan persaingan antar sekolah lainnya.

Berdasarkan latar belakang di atas, maka peneliti tertarik untuk melakukan penelitian dengan judul "Perbedaan Kualitas Layanan Pendidikan Pada Peserta didik SMA Negeri 16 Palembang dan SMA YPI Tunas Bangsa Palembang".

\section{TINJAUAN PUSTAKA}

\section{A. Definisi Sekolah}

Sekolah merupakan lembaga yang terdiri dari peserta didik atau peserta didik dengan guru yang melakukan kegiatan pembelajaran di dalam kelas. Sekolah dimulai dari jenjang pendidikan dasar hingga jenjang pendidikan menengah, hingga jenjang pendidikan tinggi.

Menurut Peraturan Menteri Pendidikan Dan Kebudayaan Republik Indonesia Nomor 17 Tahun 2017, Sekolah adalah 
Sekolah Dasar (SD), Sekolah Menengah Pertama (SMP), Sekolah Menengah Atas (SMA), Sekolah Menengah Kejuruan (SMK), atau bentuk lain yang sederajat. Status sekolah meliputi sebagai berikut:

a) Sekolah Negeri

Sekolah negeri adalah lembaga pendidikan yang diselenggarakan oleh instansi pemerintah.

b) Sekolah Swasta

Sekolah Swasta yaitu sekolah yang diselenggarakan oleh nonpemerintah/swasta, penyelenggara berupa badan berupa yayasan pendidikan yang sampai saat ini badan hukum penyelenggara pendidikan masih berupa rancangan peraturan pemerintah.

\section{B. Definisi Pendidikan}

UU RI No. 20 Tahun 2003 tentang Sistem Pendidikan Nasional, pasal 1 menyatakan bahwa pendidikan adalah usaha sadar dan terencana untuk mewujudkan suasana belajar dan proses pembelajaran agar peserta didik secara aktif mengembangkan potensi dirinya untuk memiliki kekuatan spiritual keagamaan, pengendalian diri, kepribadian, kecerdasan, akhlak mulia, serta keterampilan yang diperlukan dirinya, masyarakat, bangsa dan negara.

\section{Kualitas Pelayanan}

Menurut Sugono (2014:457), kualitas dapat didefinisikan dengan ukuran baik atau buruknya sesuatu. Kualitas juga diistilahkan dengan tingkat keunggulan. Oleh sebab itu, kualitas juga merupakan hasil dari kebaikan.

Selain itu, menurut Lovelock (2010:5) pelayanan adalah bentuk kegiatan yang membuat dan memberikan faedah kepada pengguna pada waktu dan tempat yang telah ditentukan. Pelayanan tersebut memberikan hasil dan tindakan agar terwujudnya perubahan yang diinginkan. Menurut Lovelock pengertian layanan terdiri dari 2 dimensi dalam yaitu: 1) Servive sebagai kinerja yang ditawarkan kepada orang lain. Proses tersebut tentu berkaitan pada hasil fisik dan kinerja pelayanannya tidak memiliki wujud; 2) Service sebagai kegiatan atau implementasi untuk menciptakan dan memberikan fungsi kepada para orang lain dengan waktu dan tempat tertentu sehingga adanya perubahan dan kepusan dari pelanggan.

\section{METODOLOGI PENELITIAN}

Jenis penelitian ini adalah penelitian kuantitatif komparatif. Penelitian bertujuan untuk mengetahui perbedaan kualitas pelayanan pendidikan pada siswa SMA Negeri 16 Palembang dan SMA YPI Tunas Bangsa Palembang.

Data primer dalam penelitian ini diperoleh dari responden dengan menggunakan instrumen penelitian berupa kuesioner. Jenis kuesioner adalah kuesioner tertutup. Artinya jawaban pada kuesioner sudah tersedia. Kemudian, untuk data sekunder sebagai data pendukung, diambil dari tata usaha masing-masing sekolah. Data ini digunakan untuk menggambarkan kondisi umum kedua sekolah.

Dalam penelitian ini yang menjadi populasi adalah seluruh siswa SMA Negeri 16 Palembang dan SMA YPI Tunas Bangsa Palembang.

Teknik pengambilan sampel secara proportional stratified random sampling digunakan dengan tujuan untuk memperoleh sampel yang representatif dengan melihat populasi siswa yang ada di SMA Negeri 16 Palembang dan SMA YPI Tunas Bangsa Palembang. Populasi penelitian memiliki strata kelas yakni terdiri beberapa kelas. Agar representatif dengan semua populasi maka peneliti mengambil sampel dari semua kelas yaitu kelas $\mathrm{X}, \mathrm{XI}$, dan XII dengan jumlah yang proporsional.

Sampel adalah sebanyak 335,6 atau dibulatkan menjadi 336 orang. Dari jumlah sampel tersebut ditentukanlah sebaran sampelnya berdasarkan strata kelas. Secara rincin sampel penelitian ini adalah sebagai berikut:

TABEL SAMPEL PENELITIAN

\begin{tabular}{|c|c|c|c|}
\hline No & $\begin{array}{c}\text { Kela } \\
\text { s }\end{array}$ & $\begin{array}{c}\text { SMAN 16 } \\
\text { Palembang }\end{array}$ & $\begin{array}{c}\text { SMA YPI } \\
\text { Tunas } \\
\text { Bangsa } \\
\text { Palembang }\end{array}$ \\
\hline 1. & $\mathrm{X}$ & 52 & 69 \\
\hline 2. & $\mathrm{XI}$ & 53 & 59 \\
\hline 3. & $\mathrm{XII}$ & 48 & 55 \\
\hline \multicolumn{2}{|c|}{ Jumlah } & $\mathbf{1 5 3}$ & $\mathbf{1 8 3}$ \\
\hline \multicolumn{2}{|c|}{ Total } & 336 \\
\hline
\end{tabular}


Penentuan individu yang menjadi sampel akan dilakukan dengan menggunakan teknik acak (random). Teknik ini digunakan dengan asumsi bahwa semua individu dalam populasi memiliki kesempatan yang sama untuk menjadi responden.

Teknik pengumpulan data menggunakan kuesioner atau angket. Penilaian dilakukan dengan skala likert. Skala ini terdiri atas lima kategori pilihan jawaban. Pilihan jawaban kuesioner yaitu: sangat benar (SB), benar $(B)$, ragu-ragu $(R)$, tidak benar (TB), dan sangat tidak benar (STB). Untuk angket pernyataan yang bersifat positif diberi skor 5 sampai dengan 1 , sedangkan untuk angket pernyataan negatif diberi skor 1 sampai dengan 5 . Pernyataan positif yang dimaksud adalah pernyataan yang mendukung gagasan, sedangkan pernyataan negatif adalah pernyataan yang tidak mendukung gagasan.

Dalam penelitian ini, angket akan diujicobakan kepada 30 siswa masingmasing 15 orang di SMA Negeri 16 Palembang dan 15 orang di SMA YPI Tunas Bangsa Palembang.

Dalam penelitian ini, instrumen terdiri dari butir-butir pernyataan yang telah tersedia jawabannya (kuesioner/angket tertutup). Skala skor yang dipakai adalah skala likert. Untuk mengukur validitas angket dilakukan dengan menggunakan rumus korelasi product moment. Uji validitas secara teknis akan dilakukan dengan menggunakan program SPSS.

Hasil penghitungan masing-masing butir pernyataan akan dibandingan dengan nilai kritis pada $r_{\text {tabel }}$ product moment dengan kriteria sebagai berikut:

\section{a. jika $r_{\text {hitung }}>r_{\text {tabel }}$ maka data tersebut valid \\ b. jika $r_{\text {hitung }} \leq r_{\text {tabel }}$ maka data tersebut tidak valid}

\footnotetext{
Uji reliabilitas dilakukan dengan bantuan program SPSS. Hasil penghitunganuji reliabilitas dibandingkan dengan $r_{\text {tabel }}$ product momentdengan kriteria sebagai berikut:
}

1) jika $r_{\text {hitung }}>r_{\text {tabel }}$ maka data tersebut reliabel

2) jika $r_{\text {hitung }} \leq r_{\text {tabel }}$ maka data tersebut tidak reliabel

Teknik untuk mendeskripsikan data dalam penelitian ini menggunakan rumus uji rata-rata dalam bentuk persentase. Cara menghitungnya adalah jumlah skor pelayanan yang didapat oleh masingmasing sekolah dibagi dengan skor maksimal kuesioner kemudian dikali seratus persen.

Hasil hitung persentase pelayanan pendidikan tersebut diartikan dengan memperhatikan tabel penilaian dibawah ini:

Kategori Kualitas Pelayanan Pendidikan

\begin{tabular}{|c|c|}
\hline Rata-Rata (\%) & Kategori \\
\hline$>84-100$ & Baik sekali \\
$>68-84$ & Baik \\
$>52-68$ & Cukup \\
$>36-52$ & Kurang \\
$20-36$ & Sangat kurang \\
\hline
\end{tabular}

(Sumber: diolah peneliti, 2019)

Untuk menguji kebenaran hipotesis digunakanlah uji banding atau uji-t. Secara teknis uji-t dilakukan dengan bantuan program SPSS. Hasil uji-t yaitu nilai signifikan (sig.) akan dibandingkan dengan nilai $\alpha=0.05$. Kriteria penilaian adalah sebagai berikut:

a. Jika nilai sig. $\geq \alpha=0.05$ maka $\mathrm{H}_{\mathrm{a}}$ yaitu terdapat perbedaan pelayanan pendidikan yang signifikan antara SMA Negeri 16 Palembang dengan SMA YPI Tunas Bangsa Palembang.

b. Jika nilai sig. $\leq \alpha=0.05$ maka $\mathrm{H}_{\text {o }}$ yaitu tidak terdapat perbedaan pelayanan pendidikan yang signifikan antara SMA Negeri 16 Palembang dengan SMA YPI Tunas Bangsa Palembang.

\section{HASIL DAN DISKUSI}

Deskripsi umum responden terdiri dari jenis kelamin dan usia. Adapun deskripsi umum responden tersebut dapat dilihat pada tabel di bawah ini. 
JURNAL ILMIAH MUQODDIMAH:

Jurnal IImu Sosial, Politik Dan Humaniora

Deskripsi Responden Penelitian Berdasarkan Demografi

\begin{tabular}{|c|c|c|c|}
\hline \multicolumn{2}{|c|}{ Data Demografi } & \multirow{2}{*}{$\begin{array}{c}\text { SMA Negeri } 16 \\
\text { Palembang } \\
\text { Jumlah }\end{array}$} & $\begin{array}{c}\text { SMA } \\
\text { YPI } \\
\text { Tunas } \\
\text { Bangsa }\end{array}$ \\
\hline & & & Jumlah \\
\hline \multirow[b]{2}{*}{ Jenis Kelamin } & Laki-Laki & 76 & 91 \\
\hline & Perempuan & 77 & 92 \\
\hline \multicolumn{2}{|c|}{ Total } & 153 & 183 \\
\hline \multirow{2}{*}{ Usia } & 14-15 tahun & 87 & 102 \\
\hline & 16-17 tahun & 66 & 81 \\
\hline \multicolumn{2}{|c|}{ Total } & 153 & 183 \\
\hline
\end{tabular}

Berdasarkan tabel deskripsi responden penelitian berdasarkan demografi diketahui responden SMA Negeri 16 Palembang berjenis kelamin laki-laki sebanyak 76 orang $(49,67 \%)$, sedangkan responden berjenis kelamin perempuan sebanyak 77 orang $(50,33 \%)$. Usia $14-15$ tahun pada responden SMA Negeri 16 Palembang sebanyak 87 orang $(56,86 \%)$, sedangkan pada usia 16-17 tahun sebanyak 66 orang $(43,14 \%)$. Selanjutnya, pada responden SMA YPI Tunas Bangsa berjenis kelamin laki-laki sebanyak 91 orang $(49,73 \%)$, sedangkan responden berjenis kelamin perempuan sebanyak 92 orang $(50,27 \%)$. Usia $14-15$ tahun pada responden SMA YPI Tunas Bangsa sebanyak 102 orang $(55,74 \%)$, sedangkan pada usia 16-17 tahun sebanyak 81 orang $(44,26 \%)$.

Berdasarkan hasil penelitian ditemukan bahwa jumlah sampel SMA Negeri 16 Palembang sebanyak 153 responden dengan nilai rata-rata sebesar 215,3072, sedangkan jumlah sampel SMA YPI Tunas Bangsa Palembang sebanyak 183 responden dengan nilai rata-rata sebesar 212,2842. Dengan demikian, secara rata-rata dapat disimpulkan bahwa ada perbedaan kualitas pelayanan pendidikan pada peserta didik di SMA Negeri 16 Palembang dan SMA YPI Tunas Bangsa Palembang.

Nilai Sig. Levene's Test for Equality of Variances adalah sebesar $0,553>0,05$ maka dapat diartikan bahwa varians data antara peserta didik SMA Negeri 16
Palembang dengan peserta didik SMA YPI Tunas Bangsa Palembang adalah homogen atau sama (Sujarweni, 2014:99). Sehingga penafsiran tabel output Independent Samples Test di atas berpedoman pada nilai yang terdapat dalam tabel Equal variances assumed.

Berdasarkan tabel output Independent Samples Test pada bagian Equal variances assumed diketahui nilai Sig. (2-tailed) sebesar $0,000<0,05$, maka sebagaimana dasar pengambilan keputusan dalam uji independent sample $t$ test dapat disimpulkan bahwa ada perbedaan yang signifikan (nyata) kualitas pelayanan pendidikan pada peserta didik SMA Negeri 16 Palembang dan SMA YPI Tunas Bangsa Palembang. Nilai Mean Difference adalah sebesar 3,02304. Nilai ini menunjukkan selisih kualitas pelayanan pendidikan pada peserta didik SMA Negeri 16 Palembang dan SMA YPI Tunas Bangsa Palembang. Rata-rata kualitas pelayanan pada SMA Negeri 16 Palembang dengan rata-rata kualitas pelayanan pendidikan pada SMA YPI Tunas Bangsa Palembang atau $215,3072-212,2842=3,0230$ dan selisih perbedaan tersebut adalah 1.89161 sampai 4.15447 (95\% Confidence Interval of the Difference Lower Upper).

Berdasarkan hasil tersebut secara garis besar dapat dilihat pada gambar di berikut ini :

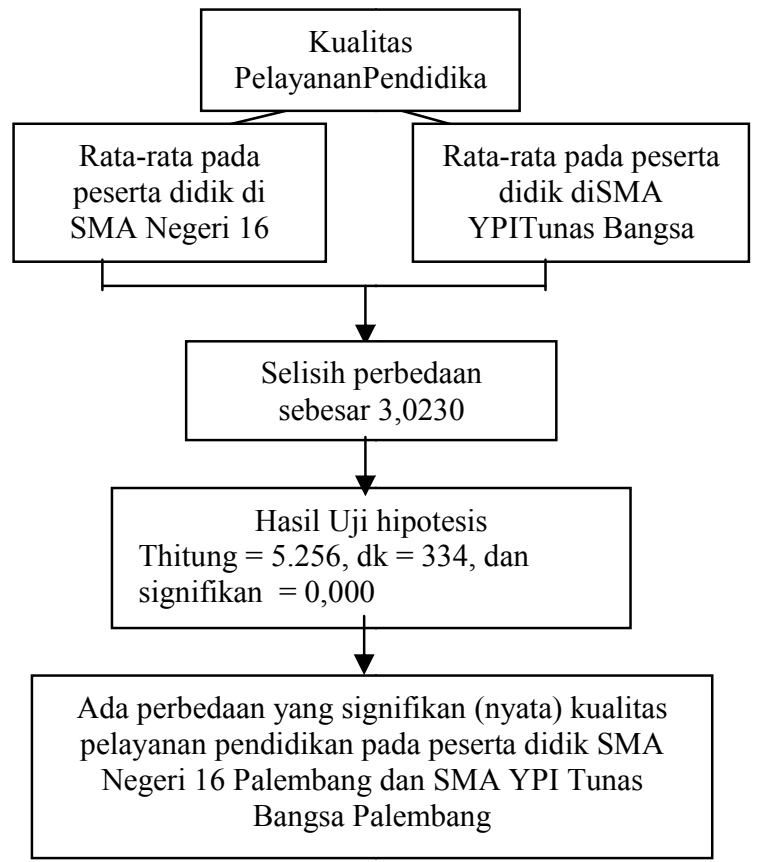


Hasil penelitian ini membuktikan bahwa ada perbedaan yang signifikan (nyata) kualitas pelayanan pendidikan pada peserta didik SMA Negeri 16 Palembang dan SMA YPI Tunas Bangsa Palembang. Berdasarkan hasil jawaban angket ditemukan perbedaan pada masing-masing indikator yang dapat dilihat pada tabel di bawah ini.

Perbedaan Rata-Rata Hasil Jawaban Angket Berdasarkan Indikator (Sumber : Data Primer 2019)

Berdasarkan tabel rata-rataperbedaan hasil jawaban angket berdasarkan indikator di atas, diketahui bahwa selisih perbedaan rata-ratatertinggi terletak pada prinsip ekologi dan keadilan sosial dan HAM yaitu sebesar 1,338905 dan 1,216329. Ini menunjukkan bahwa adanya perbedaan suatu bentuk pelayanan pendidikan yang dilakukan pada masing-masing sekolah tersebut. Selain itu, keadilan sosial dan HAM adalah pelayanan pendidikan yang menjunjung kesetaraan sosial dan penghargaan terhadap manusia. Supardi (2013:207) menjelaskan bahwa menciptakan lingkungan sekolah efektif untuk menunjang proses kegiatan belajar mengajar, memerlukan iklim sekolah yang efektif. Iklim sekolah akan efektif apabila unsur-unsur dan dimensi-dimensi yang ada di dalamnya dapat diciptakan dan dikembangkan serta dipertahankan untuk hal-hal yang sudah baik dan positif. Selanjutnya, Utami (2017:289), juga menjelaskan bahwa melalui adanya lingkungan sekolah efektif yaitu dengan keadaan yang kondusif untuk belajar, siswa dan guru dapat melangsungkan kegiatan belajar mengajar secara optimal. Lingkungan sekolah dapat dibedakan menjadi lingkungan fisik terkait dengan sarana dan prasarana dan lingkungan sosial terkait dengan hubungan atau komuniasi antar warga sekolah.

Prinsip ekologi juga telah diciptakan oleh kementrian lingkungan hidup yaitu sekolah hijau. Widodo (2017:10), konsep ini diciptakan oleh Kementerian Lingkungan Hidup. Sekolah Hijau mengajak semua penghuni sekolah untuk menciptakan lingkungan sekolah yang sehat, hijau, dan bersih. Melalui konsep Sekolah Hijau diharapkan lahir kesadaran penghuni sekolah untuk ikut berpartisipasi menciptakan lingkungan pembelajan yang sehat, hijau dan menyenangkan. Berbekal lingkungan hidup yang hijau, bebas polusi diharapkan mampu mendukung terciptanya suasana belajar yang kondusif dan penghuni sekolah juga nyaman untuk berinteraksi. Selanjutnya dengan

\begin{tabular}{|c|c|c|c|c|}
\hline No. & $\begin{array}{l}\text { Prinsip } \\
\text { Ekologi }\end{array}$ & $\begin{array}{l}\text { Keadian } \\
\text { Sosial dan } \\
\text { Hak Asasi } \\
\text { Manusia }\end{array}$ & $\begin{array}{l}\text { Menghargai } \\
\text { yang Lokal }\end{array}$ & $\begin{array}{l}\text { Prinsip } \\
\text { Proses }\end{array}$ \\
\hline $\begin{array}{l}\text { SMA Negeri } \\
16 \\
\text { Palembang }\end{array}$ & $\begin{array}{c}28,3006 \\
5\end{array}$ & 75,35294 & 58,51634 & 53,13725 \\
\hline $\begin{array}{l}\text { SMA YPI } \\
\text { Tunas } \\
\text { Bangsa } \\
\text { Palembang. }\end{array}$ & $\begin{array}{c}26,9617 \\
5\end{array}$ & 74,13661 & 58,47541 & 52,71038 \\
\hline Selisih & 1,338905 & 1,216329 & 0,04093 & 0,426872 \\
\hline
\end{tabular}

lingkungan yang hijau diharapkan mampu mendukung lahirnya tindakan atau perbuatan yang baik sehingga beragam bentuk pelanggaran HAM bisa diredam.

Pada indikator keadilan sosial dan hak asasi manusia (HAM) merupakan rata-rata jawaban angket yang tertinggi pada peserta didik di SMA Negeri 16 Palembang dan SMA YPI Tunas Bangsa Palembang. Wahab (2017:1) menjelaskan bahwa salah satu tujuan pendirian negara Indonesia adalah mencerdaskan kehidupan bangsa, sebagaimana termaktub pada pembukaan UUD 1945. Artinya bahwa pendidikan merupakan sesuatu yang sangat penting dan berharga dalam kehidupan bangsa Indonesia, terlebih-lebih sangat berarti ketika peranannya dalam membekali setiap insan Indonesia untuk menghadapi tantangan jaman yang semakin kompleks dan kompetitif.

Keadilan merupakan kata kunci dalam konteks ini. Untuk mengetahui makna keadilan lebih mendalam, secara konseptual di antaranya dapat mengacu pada pendapat Murtadla al Muthahhari (Nurkholis Madjid, 1992) bahwa keadilan dapat dipahami melalui empat pengertian pokok. Pertama, keadilan mengandung pengertian perimbangan atau keadaan seimbang (mawzan, balanced), tidak pincang. Kedua, keadilan mengandung makna persamaan (musawah, ega-lite) dan 
tiadanya diskriminasi dalam bentuk apapun. Maka salah satu maksud ungkapan bahwa seseorang telah bertindak adil ialah jika ia memperlakukan semua orang secara sama. Ketiga, pengertian keadilan tidak utuh jika kita tidak memperhatikan maknanya sebagai pemberian perhatian kepada hakhak pribadi dan penunaian hak kepada siapa yang berhak (ithaa kulli dzii haqqq haqqahuu). Maka kedzaliman dalam kaitannya dengan pengertian ini ialah perampasan hak dari orang yang berhak, dan pelanggaran hak orang yang tak berhak. Keempat, keadilan Tuhan (al-'Ad'l al-Ilaahii), berupa kemurahan-Nya dalam melimpahkan rahmat kepada sesuatu atau seseorang setingkat dengan kesediannya untuk menerima eksistensi dirinya sendiri dan pertumbuhannya ke arah kesempurnaan.

Mengetahui ada beragam

pelanggaran HAM di sekolah, masyarakat tidak berpangku tangan. Berbagai komunitas maupun individu berusaha mengembangkan sebuah proses pembelajaran yang lebih humanis, sesuai dengan kebutuhan dan perkembangan anak, proses pendidikan yang menyeimbangkan kemampuan akademis dengan perkembangan psikologis, karakter, mental/jiwa serta sosial anak dan pendidikan yang "membebaskan" anak dari tuntutan akademis. Serta yang terpenting mencoba menerapkan nilai-nilai dasar HAM di sekolahnya.

\section{KESIMPULAN}

Berdasarkan hasil temuan penelitian di lapangan mengenai Perbedaan Kualitas Layanan Pendidikan Pada Peserta didik SMA Negeri 16 Palembang dan SMA YPI Tunas Bangsa Palembang, maka peneliti dapat menarik kesimpulan bahwa kualitas layanan pendidikan pada peserta didik di SMA Negeri 16 Palembang termasuk dalam kategori baik, sedangkan kualitas layanan pendidikan pada peserta didik di SMA YPI Tunas Bangsa Palembang termasuk dalam kategori cukup.Berdasarkan perhitungan statitik ditemukan nilai Sig. (2-tailed) sebesar $0,000<0,05$, sehingga dapat disimpulkan bahwa ada perbedaan yang signifikan (nyata) kualitas pelayanan pendidikan pada peserta didik SMA Negeri
16 Palembang dan SMA YPI Tunas Bangsa Palembang.

\section{DAFTAR PUSTAKA}

Direktorat Jenderal Pendidikan Dasar dan Menengah, Direktorat Jenderal Pendidikan Dasar dan Menengah, Kementerian Pendidikan dan Kebudayaan tahun 2016 tentang Panduan Kuesioner Pengumpulan Data Mutu Pendidikan untuk Sekolah Menengah Atas (SMA).

Fasani, Rizkan Faif. 2016. Pengaruh Kualitas Layanan Pendidikan terhadap Kepuasan Siswa di SMA MTA Surakarta. Fakultas Keguruan dan IImu Pendidikan Universitas Sebelas Maret Surakarta.

Lovelock, Christopher. 2002. Service Marketing In Asia. Prentice Hall Inc Singapore

Mendikbud. 2016. Penilaian Kualitas Pendidikan Harus Menyeluruh. Artikel antaranews. Online. www.antaranews.com/berita.

Diakses tanggal 7 Mei 2018.

Mongi, Charles E. 2017. Perbandingan SMA Negeri Dan SMA Swasta Berdasarkan Nilai Akreditasi dan Nilai Ujian Nasional Menggunakan Uji-T di Kota Manado. Jurnal IImiah Sains Vol. 16 No. 2, Oktober 2016.

Munirah. 2015. Sistem Pendidikan di Indonesia: Antara Keinginan dan Realita. Auladuna, Vol. 2 No. 2 Desember 2015: 233-245 234.

Rahayu, Indah. 2017. Perbedaan Kualitas Layanan Sekolah Menengah Kejuruan Negeri dan Swasta di Kabupaten Ngawi. Jurnal Administrasi Pendidikan, Fakultas Ilmu Pendidikan Universitas Negeri Malang.

Supardi. 2013. Sekolah Efektif: Konsep Dasar dan Praktiknya. Jakarta: Rajawali Pers. 
Utami, Desi Wahyu. 2017. Kontribusi Kebersihan Lingkungan Sekolah terhadap Motivasi Belajar Siswa Kelas V Sekolah Dasar. Jurnal Pendidikan Guru Sekolah Dasar Edisi 4 Tahun ke-6.

UU RI No. 20 Tahun 2003 tentang Sistem Pendidikan Nasional

Wartono, Kostrad Hari. 2015. Pondok Pesantren Internasional di Surakarta Dengan Pendekatan Arsitektur Islam. Naskah Publikasi. Program Studi Arsitektur, Fakultas Teknik, Universitas Muhammadiyah Surakarta.

Widodo (2017. Sekolah Ramah Hak Asasi Manusia (SR HAM): Solusi Menghapus Pelanggaran HAM di Sekolah. Jakarta: Penyuluh Ham Komnas HAM.

Zeithaml, Valarie A. and Bitner, Mary Jo. 2002. Service Marketing. New York: McGraw Hill Inc, Int"I Edition. 